Illinois State University

ISU ReD: Research and eData

Theses and Dissertations

$1-27-2017$

\title{
Do Healthcare Professionals With High Weight Biases Provide Different Quality Of Care To Obese Compared To Normal Weight Patients?
}

Justine Leigh Seymour

Illinois State University, jlseym1@ilstu.edu

Follow this and additional works at: https://ir.library.illinoisstate.edu/etd

Part of the Health and Medical Administration Commons

\section{Recommended Citation}

Seymour, Justine Leigh, "Do Healthcare Professionals With High Weight Biases Provide Different Quality Of Care To Obese Compared To Normal Weight Patients?" (2017). Theses and Dissertations. 709.

https://ir.library.illinoisstate.edu/etd/709

This Thesis is brought to you for free and open access by ISU ReD: Research and eData. It has been accepted for inclusion in Theses and Dissertations by an authorized administrator of ISU ReD: Research and eData. For more information, please contact ISUReD@ilstu.edu. 


\title{
DO HEALTHCARE PROFESSIONALS WITH HIGH WEIGHT BIASES PROVIDE DIFFERENT QUALITY OF CARE TO OBESE COMPARED TO NORMAL WEIGHT PATIENTS?
}

\author{
Justine Leigh Seymour
}

\section{Pages}

Though weight bias has been acknowledged in the health field, it is less understood if and how weight bias affects quality of care. The purpose of this study was to determine if weight bias exhibited by healthcare professionals (HCPs) impacts quality of healthcare provided to obese individuals. HCPs ( $\mathrm{n}=220 ; 88 \%$ female, $87 \%$ nurses) in the Midwest region of the United States were recruited to complete an online survey. Participants completed the Attitude Towards Obese Persons scale (ATOP) to assess weight bias and responded to hypothetical patient scenarios to evaluate quality of care. A median split was calculated for ATOP scores to divide participants into high or low weight bias groups. Within these groups, thematic analysis was used to uncover themes in quality of care based upon participants' responses to scenarios. Results revealed overall that diet and exercise modifications were the most common treatment methods. HCPs in the high weight bias group gave more specific diet and exercise recommendations and offered health advice regarding weight loss. Additionally, in both weight bias groups, obese patients were started on pharmaceutical therapies sooner. A word count revealed "educate" and "encourage" were used in similar frequencies (69-73\%) when counseling patients; however, in the high weight bias group, these words were used less frequently $(25 \%)$ for obese patients. The findings of this study suggest a need to educate HCPs on the importance of empathy and 
compassion when providing treatment to all patients, regardless of weight, to improve patient outcomes.

KEYWORDS: Weight Bias, Quality of Care, Healthcare Professionals, Healthcare, Obesity 
DO HEALTHCARE PROFESSIONALS WITH HIGH WEIGHT BIASES PROVIDE DIFFERENT QUALITY OF CARE TO OBESE COMPARED TO

NORMAL WEIGHT PATIENTS?

JUSTINE LEIGH SEYMOUR

A Thesis Submitted in Partial Fulfillment of the Requirements for the Degree of

MASTER OF SCIENCE

Department of Family and Consumer Sciences

ILLINOIS STATE UNIVERSITY 
(C) 2017 Justine Leigh Seymour 
DO HEALTHCARE PROFESSIONALS WITH HIGH WEIGHT BIASES PROVIDE DIFFERENT QUALITY OF CARE TO OBESE COMPARED TO NORMAL WEIGHT PATIENTS?

JUSTINE LEIGH SEYMOUR

COMMITTEE MEMBERS:

Julie Schumacher, Chair

Rachel Vollmer

Jennifer Barnes 


\section{ACKNOWLEDGMENTS}

I'd like to extend a great thanks to Rachel Vollmer who inspired me to pursue this thesis topic and worked closely with me on this project. I recognize that she did not have to continue advising me through this project once leaving Illinois State University and I appreciate the commitment and generosity she has shown in being an active thesis committee member. Rachel has been an impeccable research mentor and I owe much of this study to her guidance.

The other members of my thesis committee, Julie Schumacher and Jennifer Barnes, deserve a great thanks as well. Thank you for making room in your busy schedules to help me through this process. Being a rookie to conducting research, I have certainly grown from working with experienced researchers like yourselves.

Completing a thesis would have been challenging without the support of my fellow classmates, so thank you to my fellow dietetic interns who always offered support and friendship.

Furthermore, thank you to my support system who never fails to keep me grounded in hard times. Mom, Dad, Ryan, and Jared, thank you for always pushing me towards my goals and seeing me through to achievement. I could not ask to be surrounded by a better team of strength and encouragement. 


\section{CONTENTS}

Page

ACKNOWLEDGMENTS

$\begin{array}{lll}\text { CONTENTS } & \text { ii }\end{array}$

TABLES

CHAPTER I: HEALTHCARE PROFESSIONALS WEIGHT BIAS VERSUS QUALITY OF

CARE: A STUDY 1

$\begin{array}{ll}\text { Introduction } & 1\end{array}$

Methodology 3

Sample Population and Recruitment 3

Data Collection 3

$\begin{array}{ll}\text { Data Analysis } & 4\end{array}$

$\begin{array}{ll}\text { Results } & 5\end{array}$

Identical Recommendations $\quad 8$

Specificity in Lifestyle Recommendations 99

Medication Recommendations $\quad 10$

$\begin{array}{ll}\text { Weight Loss } & 10\end{array}$

Language 11

$\begin{array}{ll}\text { Discussion } & 13\end{array}$

$\begin{array}{ll}\text { Conclusion } & 17\end{array}$

CHAPTER II: EXTENDED LITERATURE REVIEW 18

$\begin{array}{ll}\text { Obesity Prevalence } & 18\end{array}$

$\begin{array}{ll}\text { Treatment of Obesity } & 19\end{array}$ 
$\begin{array}{ll}\text { Weight Bias } & 21\end{array}$

Healthcare Professionals and Weight Bias $\quad 23$

$\begin{array}{ll}\text { Quality of Care } & 26\end{array}$

$\begin{array}{lr}\text { REFERENCES } & 28\end{array}$

APPENDIX A: DATA COLLECTION TOOLS 35 


\section{TABLES}

Table

Page

1. Characteristics of Healthcare Professionals $(n=220)$

2. Correlations Between ATOP Score and Age, Years Experience, Self-Reported BMI, and Actual BMI

3. Examples of Identified Themes in HCP Responses 


\section{CHAPTER I: HEALTHCARE PROFESSIONALS WEIGHT BIAS VERSUS QUALITY OF}

\section{CARE: A STUDY}

\section{Introduction}

Weight bias, defined as negative attitudes or judgments of an overweight or obese individual based on stereotypes, has been reported in a variety of environments including healthcare settings (Pomeranz, 2008; Puhl \& Heuer, 2010). Weight bias can generate stigma and discrimination, which have been identified as barriers to healthcare and healthy lifestyle behaviors in other vulnerable populations such as HIV/AIDS patients (Pomeranz, 2008). People who feel stigmatized in healthcare settings, including obese individuals, report many barriers to seeking healthcare (Brown, Thompson, Tod, \& Jones, 2006; Buxton \& Senthen, 2013), thus perpetuating health disparities and negatively effecting obese individuals.

A literature review exploring HCP attitudes towards obese persons found that HCPs, including physicians, nurses, dietitians, psychologists, and obesity specialists, exhibited weight biases towards overweight and obese patients (Budd, Mariotti, Graff \& Falkenstein, 2011). Higher levels of weight bias were identified in younger health professionals with less experience working with obese patients (Schwartz, Chambliss, Brownell, Blair \& Billington, 2003; Teachman \& Brownell, 2001). Furthermore, a study by Miller et al. (2013) found that 72\% of surveyed medical students exhibited weight bias, $56 \%$ had unconscious weight biases and only $23 \%$ of students who had weight biases were aware of this weight bias. The negative attitude of HCPs towards obese patients may inadvertently affect quality of healthcare delivered to obese patients.

Weight bias and quality of care are separate constructs, however, and it has been suggested that there is a need to understand whether HCP weight biases affect quality of 
healthcare (Budd et al., 2011). While it has been well established that many HCPs have weight biases or negative attitudes towards obese individuals (Sikorsky et al., 2013, Budd et al., 2011; Phelan et. al., 2015; Puhl and Heuer, 2010; Miller et al., 2008; Puhl, Wharton \& Heuer, 2009; Schwartz et al., 2003), it is less understood whether having weight biases affects quality of healthcare provided. It has been observed that HCPs perceive obese patients as non-adherent to health recommendations, show obese patients less respect, and provide less health education to obese patients (Huizinga, Bleich, Beach, Clark, \& Cooper, 2010; Huizinga, Cooper, Bleich, Clark, \& Beach, 2009; Bertakis \& Azari, 2005). Furthermore, physicians tend to act more distanced from, order more tests, and spend significantly less time with obese patients compared to normal weight patients (Hebl, Xu, \& Mason, 2013). While these negative quality of care outcomes have been recognized in the health field, they have not been explicitly connected to HCP weight bias. In fact, studies that have evaluated weight bias's effect of quality of care have concluded that weight bias does not affect clinical recommendations (Persky \& Eccleston, 2011; Budd et al., 2011; Ma, Xiao \& Strafford, 2009). Therefore, there is a need to understand whether differences in quality of care delivered to obese patients is directly affected by HCP weight bias.

Understanding how quality of care is affected by negative attitudes towards obese people may provide insight on how to improve the health of this population. The purpose of this study was to evaluate whether healthcare professionals in the Midwest region of the United States exhibit weight bias towards overweight and obese individuals and to determine if and how weight bias affects quality of care. The hypotheses were: 1) Those in the high weight bias group will provide lower quality of care to obese patients compared to the low weight bias group. 2) When counseling obese patients, HCPs in the high weight bias group will provide more 
recommendations related to weight loss than the health issue compared to the low weight bias group.

\section{Methodology}

\section{Sample Population and Recruitment}

Prior to participant recruitment, this protocol was approved by the Illinois State University Institutional Review Board. Convenience sampling was used to select the participants for this study. Inclusion criteria for this study included: must be a healthcare professional practicing in the Midwest region of the United States (Illinois, Indiana, Iowa, Kansas, Michigan, Minnesota, Missouri, Nebraska, North Dakota, Ohio, South Dakota and Wisconsin), be over the age of 18, and be able to read and write in English. Invitations to complete this study were distributed by nursing professionals to hospital employees on a voluntary basis. Participants provided informed consent by clicking "agree" on the informed consent form prior to accessing the survey questions. The Informed Consent Form is included in Appendix A.

\section{Data Collection}

After providing informed consent, participants completed several questionnaires via an online survey. Demographic data including age, gender, occupation, and years of experience in the field preceded weight bias and quality of care measurements. The 20-item Attitudes Towards Obese Persons (ATOP) Scale, $(\alpha=.72)$ a previously validated weight bias assessment tool (DePierre \& Puhl, 2012) was used to evaluate weight bias. This specific tool was selected for its known reliability, available access, ease of completion, and reasonable length. ATOP scores were calculated using the published scoring guidelines. The ATOP Scale and scoring instructions are included in Appendix A. Higher ATOP scores denote low weight bias, and low ATOP scores denote high weight bias. 
Quality of care was measured by open-ended responses to hypothetical patient scenarios. Short scenarios or vignettes have been previously validated as effective methods to evaluate quality of health care (Peabody, Luck, Glassman, Dresselhaus \& Lee, 2000; Kaptanoglu \& Aktas, 2013). Each scenario contained information about a hypothetical patient's height, weight, body mass index (BMI), sex, and new diagnosis with hypercholesterolemia. Each pair of scenarios were identical with the exception of patient BMI and sex and were accompanied by a picture of a male or female with the BMI described in the scenario. HCPs received the male or female scenarios at random. These silhouettes of individuals of various BMI categories have been previously validated to measure weight concepts (Harris, Bradlyn, Coffman, Gunel, \& Cottrell, 2008) such as weight bias. Quality of care was measured by analyzing how the HCP responded to the scenario and whether he or she responded differently to the obese patient versus the normal weight patient. Scenarios are included in Appendix A.

Participants who completed the survey had the opportunity to enter their name and contact information in a raffle for one of two $\$ 100$ Amazon gift cards upon completion by clicking on a link to enter their information in a separate window. Raffle information was not associated with the survey data, and all survey response information remained anonymous.

\section{Data Analysis}

Participant demographic data and ATOP scores were analyzed using descriptive statistics in SPSS. For the ATOP scale, a median split was calculated to divide participants into "high weight bias" and "low weight bias" groups. A bivariate correlation was run between ATOP score and age, self-reported BMI, and years of experience with significance set at $\mathrm{p}<0.05$. Responses to scenarios by bias groups were then used to identify themes or categories through thematic 
analysis in the qualitative responses of the participants. These themes helped identify any differences in quality of care based on weight bias.

For the qualitative analysis procedure, all scenario responses were coded to identify themes among the high- and low-weight bias groups. Responses were meant to be individual units of data that fit into a theme identified separately by a graduate student and faculty member. The graduate student and faculty member then met to discuss themes and reach consensus. Themes formed in the high and low weight bias groups were then compared to identify any similarities or differences in quality of care.

\section{Results}

A total of 355 people accessed the online survey and 135 responses were excluded for incomplete responses, resulting in a final sample of $220 \mathrm{HCPs}$. Participants were mostly female (88\%) nurses (87\%) practicing in Illinois (99\%) (Table 1). Most respondents were 26-35 years old (35.9) and 50\% have worked in healthcare for less than ten years. The ATOP score of participants ranged from 35-117 (high weight bias to low weight bias respectively) with a mean ATOP score of 73.18 . 
Table 1

Characteristics of Healthcare Professionals $(n=220)$

\begin{tabular}{|c|c|c|}
\hline Variable & $\mathrm{n}$ & $\%$ \\
\hline \multicolumn{3}{|l|}{ Gender } \\
\hline Male & 26 & 11.8 \\
\hline Female & 193 & 87.7 \\
\hline \multicolumn{3}{|c|}{ Years of Experience } \\
\hline$<5$ & 56 & 25.5 \\
\hline $6-10$ & 54 & 24.5 \\
\hline $11-15$ & 29 & 13.2 \\
\hline $16-20$ & 38 & 17.3 \\
\hline $21-25$ & 15 & 6.8 \\
\hline $26-30$ & 17 & 7.7 \\
\hline$>30$ & 11 & 5.0 \\
\hline \multicolumn{3}{|l|}{ Age (years) } \\
\hline$<25$ & 23 & 10.5 \\
\hline $26-35$ & 79 & 35.9 \\
\hline $36-45$ & 51 & 23.2 \\
\hline $46-55$ & 37 & 13.6 \\
\hline $56-65$ & 30 & 13.6 \\
\hline$>65$ & 0 & 0 \\
\hline \multicolumn{3}{|c|}{ Self-Report Weight Category } \\
\hline Underweight & 1 & 0.5 \\
\hline Normal & 95 & 43.2 \\
\hline Overweight & 99 & 45.0 \\
\hline Obese & 23 & 10.5 \\
\hline
\end{tabular}




\begin{tabular}{lcc}
\hline Variable & $\mathrm{n}$ & $\%$ \\
\hline Race/Ethnicity & & \\
Caucasian/White & 199 & 90.5 \\
Asian & 7 & 3.2 \\
African American & 6 & 2.7 \\
Hispanic & 1 & 0.5 \\
Other & 5 & 2.3 \\
Profession & & \\
Physician & 1 & 0.5 \\
Nurse & 191 & 86.8 \\
Nurse Practitioner & 12 & 5.5 \\
Dietitian & 2 & 0.9 \\
Other & 14 & 6.3 \\
& Mean & SD \\
Attitudes Towards Obese Persons Scale (ATOP) & 73.18 & 15.25 \\
\hline
\end{tabular}

When examining relationships between demographic characteristics and weight bias, it was found that there was a significant negative correlation between age and ATOP score $(\mathrm{r}=$ $-0.185, \mathrm{p}<0.01)$ and years experience and ATOP score $(\mathrm{r}=-0.171, \mathrm{p}<0.05)$, indicating that older individuals and those with more healthcare experience expressed more weight bias. Self-reported BMI or calculated BMI were not significantly correlated with ATOP score. These correlations are illustrated in Table 2. 
Table 2

Correlations Between ATOP Score and Age, Years Experience, Self-Reported BMI, and Actual BMI

\section{ATOP Score}

\begin{tabular}{lcccc} 
& Age & Years Experience & Self-Reported BMI & Actual BMI \\
\hline Pearson's Correlation & -.185 & -.171 & -.010 & -.001 \\
Significance (2-tailed) & .006 & .011 & .887 & .991 \\
$\mathrm{~N}$ & 220 & 220 & 218 & 220 \\
\hline
\end{tabular}

Overall, diet and exercise modifications were the most common treatment methods recommended by high and low weight bias groups, followed by medication. When comparing the high versus low weight bias groups, a total of five major themes were identified from the qualitative data: 1) identical recommendations, 2) specificity in lifestyle recommendations, 3) medication recommendations, 4) weight loss, and 5) language. Table 3 includes examples of responses that were coded into these categories.

\section{Identical Recommendations}

There were no thematic differences noted between recommendations given to the normal weight and obese patients in $44 \%$ of high weight bias responses and $56 \%$ of low weight bias responses. This means that if HCPs discussed diet and exercise with the normal weight patient, they also discussed these same topics with the obese patient. Responding to both patients with "encourage an exercise routine and [a] diet low in fat" (HCP\#A40, low weight bias group) or "I would give this [obese] patient the same information as the previous [normal weight] patient" 
(HCP\#A85, high weight bias group) were coded as identical recommendations. This suggests that many HCPs, particularly those with low weight bias, offer similar recommendations to patients regardless of their weight. Offering identical recommendations may indicate no difference in quality of care delivered to the obese versus normal weight patient.

\section{Specificity in Lifestyle Recommendations}

More HCPs in the high weight bias category took more liberty in providing diet recommendations to the hypothetical obese patient compared to the normal weight patient. While HCPs in both weight bias groups used general terms such as "heart healthy diet," "low fat/low cholesterol diet," and "diet modifications" with all patients, "strict" (HCP\#C99, high weight bias group) and "drastic diet modifications" (HCP\#C12, high weight bias group) were recommended to obese patients. HCPs in the high weight bias group provided specific calorie and carbohydrate recommendations to the obese patient only by recommending "eating a heart healthy diet under 1800 calories a day" (HCP\#A55, high weight bias group), or a "low carb, high protein diet" (HCP\#C166, high weight bias group). The low weight bias group referred more patients, normal weight and obese, to nutrition professionals (i.e. Registered Dietitian Nutritionists) compared to their high weight bias counterparts.

A similar theme emerged when addressing exercise modifications. More HCPs in the high weight bias group assumed the normal weight patient could "add some walking" or "increase her exercise" routine where the obese patient should "start walking" or "begin an exercise program" (HCP\#A19, high weight bias group \& HCP\#A75, high weight bias group). The low weight bias group tended to advise both patients to "increase physical activity level" or "become more active," and not make assumptions about the patient's current exercise habits. It was noted that HCPs in both groups encouraged "higher intensity workout regimen[s]" 
(HCP\#A145, low weight bias group) in the obese population, recommending "working out 3-4 times a week" or "30-60 minutes per day" versus the "2-3 times a week" or "30 minutes per day" deemed sufficient for the normal weight population (HCP\#C150, low weight bias group \& HCP\#C120, high weight bias group respectively).

\section{Medication Recommendations}

HCPs in both weight bias groups were more likely to start obese patients on statin drugs immediately, where they would often recommend statins to normal weight patients once lifestyle modifications proved ineffective. This prominent theme was observed in both groups of responders but more frequently in the high weight bias group. For instance, one HCP suggested the normal weight patient "may be a candidate for cholesterol medication if diet and exercise don't improve his blood work" whereas "a cholesterol pill along with diet and exercise would be a more ideal treatment for this patient” (HCP\#C151, low weight bias group). Many HCPs, regardless of weight bias, mentioned statin drugs as part of treatment only for the obese individual. For example, one participant wrote the "only difference would [be to] start her on a medication" (HCP\#A19, high weight bias group).

\section{Weight Loss}

Patient weight was addressed more frequently by HCPs in the high weigh bias group for the obese patients and lifestyle modifications were sometimes addressed in the sole context of weight loss, not for improving cholesterol levels. For instance, HCPs recommended the obese patient "needing to start exercising to lose weight," "controlling calories in an effort to lose 35 or more pounds," and needing a "diet and exercise regimen in order to lose his extra weight" (HCP\#A62, high weight bias group; HCP\#C88, high weight bias group \& HCP\#C151, low weight bias group). On the contrary, diet and exercise modifications in the normal weight 
counterparts were aimed towards achieving healthy cholesterol levels. Some HCPs responded to normal weight patients by "prais[ing] her for her effort" of maintaining a healthy weight, and considering cardiovascular exercise “even though he isn't obese” (HCP\#A42, high weight bias group \& HCP\#C90, low weight bias group).

\section{Language}

A simple word count revealed "educate" and "encourage" were used $46 \%$ less frequently by HCPs in the high weight bias group with obese patients, compared HCPs in the high weight bias group with normal weight patients and HCPs in the low bias group will all patients. "Educate" and "encourage" carry positive connotations and allude to a setting of friendly guidance and growth. The fact that HCPs with high bias did not utilize these teaching words with obese patients suggests a less friendly, non-empathetic feel in the given provider-patient relationship, which may negatively impact quality of care.

Table 3

Examples of Identified Themes in HCP Responses

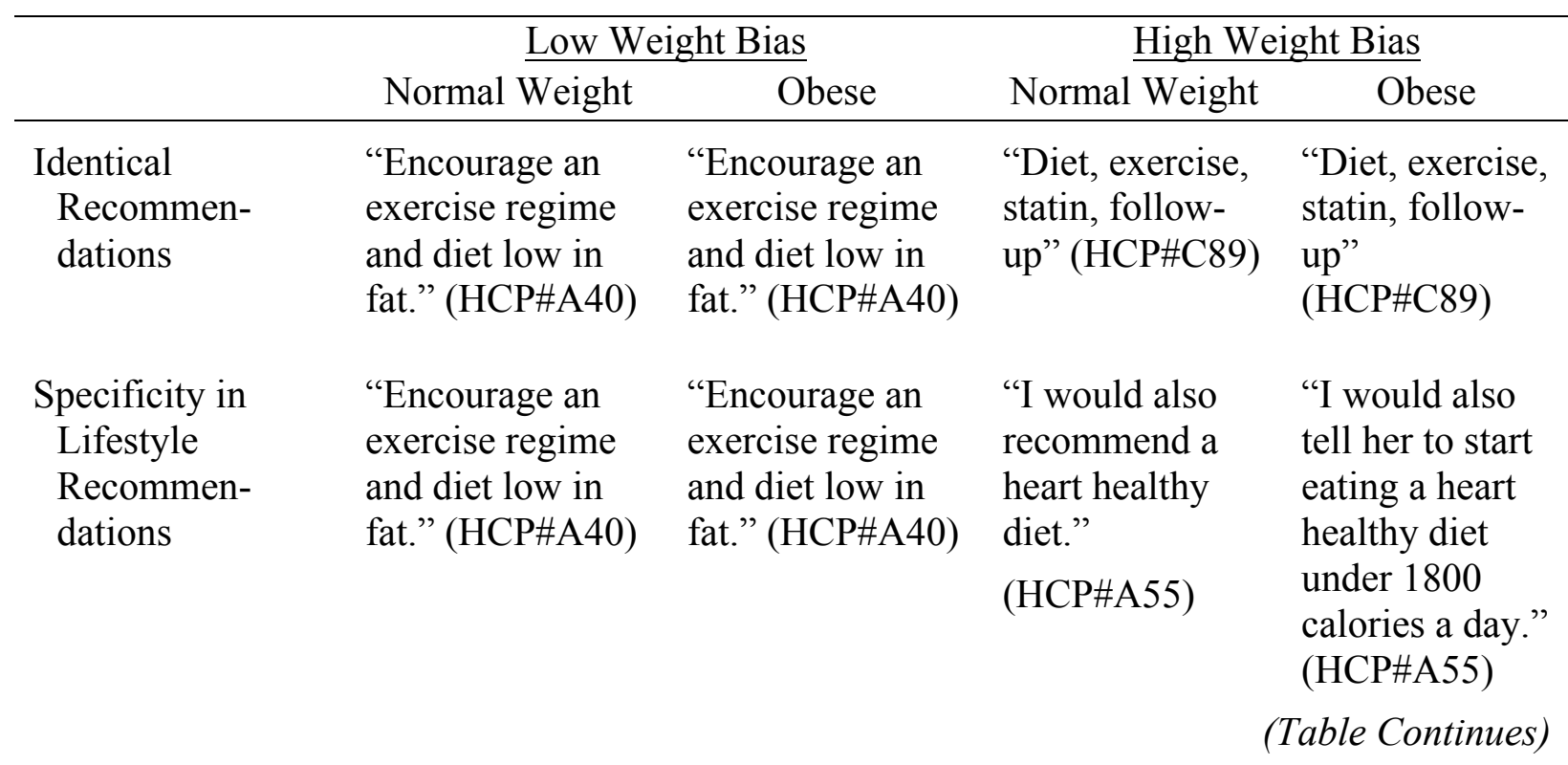




\begin{tabular}{|c|c|c|c|c|}
\hline & \multicolumn{2}{|c|}{$\underline{\text { Low Weight Bias }}$} & \multicolumn{2}{|c|}{ High Weight Bias } \\
\hline & Normal Weight & Obese & Normal Weight & Obese \\
\hline $\begin{array}{l}\text { Medication } \\
\text { Recommen- } \\
\text { dations }\end{array}$ & $\begin{array}{l}\text { "The patient may } \\
\text { be a candidate for } \\
\text { cholesterol } \\
\text { medications if } \\
\text { diet and exercise } \\
\text { don't improve his } \\
\text { blood work." } \\
\text { (HCP\#C151) }\end{array}$ & $\begin{array}{l}\text { "A cholesterol } \\
\text { pill along with } \\
\text { diet and exercise } \\
\text { would be more } \\
\text { of an ideal } \\
\text { treatment for this } \\
\text { patient." } \\
\text { (HCP\#C151) }\end{array}$ & $\begin{array}{l}\text { "Repeat her } \\
\text { lipid profile to } \\
\text { see her she is } \\
\text { improving prior } \\
\text { to starting } \\
\text { medications" } \\
\text { (HCP\#A19) }\end{array}$ & $\begin{array}{l}\text { "Only } \\
\text { difference } \\
\text { would start her } \\
\text { on a } \\
\text { medication to } \\
\text { help lower her } \\
\text { levels." } \\
\text { (HCP\#A19) }\end{array}$ \\
\hline $\begin{array}{l}\text { Weight Loss } \\
\text { Recommen- } \\
\text { dations }\end{array}$ & $\begin{array}{l}\text { "I would explain } \\
\text { the lab result and } \\
\text { potential risk for } \\
\text { Cardiovascular } \\
\text { disease. } \\
\text { Discussing each } \\
\text { item of the } \\
\text { cholesterol } \\
\text { profile. I would } \\
\text { discuss possible } \\
\text { treatment options } \\
\text { including diet } \\
\text { and activity." } \\
\text { (HCP\#A014) }\end{array}$ & $\begin{array}{l}\text { "I would discuss } \\
\text { the lab results } \\
\text { and the possible } \\
\text { risk factors for } \\
\text { cardiovascular } \\
\text { disease. I would } \\
\text { also discuss } \\
\text { possible } \\
\text { treatment options } \\
\text { including diet } \\
\text { and activity." } \\
\text { (HCP\#A014) }\end{array}$ & $\begin{array}{l}\text { "Encourage } \\
\text { increasing } \\
\text { activity levels } \\
\text { while not at } \\
\text { work. } \\
\text { Encourage diet } \\
\text { that includes } \\
\text { fiber, whole } \\
\text { grains, lean } \\
\text { protein, and } \\
\text { judicious } \\
\text { saturated fats." } \\
\text { (HCP\#C88) }\end{array}$ & $\begin{array}{l}\text { "This patients } \\
\text { diet should } \\
\text { focus on } \\
\text { controlling } \\
\text { calories in an } \\
\text { effort to lose } \\
35 \text { or more } \\
\text { pounds. In } \\
\text { order to lose } \\
\text { weight, } \\
\text { increasing } \\
\text { activity will } \\
\text { also benefit } \\
\text { this patient." } \\
\text { (HCP\#C88) }\end{array}$ \\
\hline Language Style & $\begin{array}{l}\text { "Evaluate and } \\
\text { teach on diet, } \\
\text { encourage and } \\
\text { teach about } \\
\text { exercise regime, } \\
\text { start on low dose } \\
\text { medication." } \\
\text { (HCP\#C52) }\end{array}$ & $\begin{array}{l}\text { "Evaluate and } \\
\text { teach on diet, } \\
\text { encourage and } \\
\text { teach about } \\
\text { exercise regime, } \\
\text { start on low dose } \\
\text { medication." } \\
\text { (HCP\#C52) }\end{array}$ & $\begin{array}{l}\text { "I would } \\
\text { encourage a } \\
\text { change in life } \\
\text { style to include } \\
\text { more physical } \\
\text { activity and } \\
\text { exercise. I } \\
\text { would also } \\
\text { educate the } \\
\text { patient on food } \\
\text { choices that are } \\
\text { low in } \\
\text { cholesterol." } \\
\text { (HCP\#A21) }\end{array}$ & $\begin{array}{l}\text { "I would } \\
\text { recommend the } \\
\text { patient try and } \\
\text { lose weight } \\
\text { through diet } \\
\text { and exercise." } \\
\text { (HCP\#A21) }\end{array}$ \\
\hline
\end{tabular}




\section{Discussion}

Overall, thematic analysis revealed that HCP responses to scenarios were similar regardless of weight bias, however, differences also emerged. HCPs with high weight bias offered different recommendations to obese patients more often than HCPs with low weight bias. Differences in recommendations delivered to obese patients included more specific diet and exercise advice, emphasis on pharmaceutical intervention, prominence of lifestyle modifications aimed towards weight loss, and the use of less empathetic language. As a whole, these seemingly small contrasts in care delivery may create a different healthcare experience for the obese versus normal weight patients.

The language style theme noted in this study is consistent with past studies evaluating weight bias in healthcare settings. Phelan et al. (2015), highlighted that HCPs spend less time giving obese patients health education compared to their normal weight counterparts. While this study did not measure time, the word frequency, revealing that "educate" and "encourage" were used less by HCPs with high weight bias when counseling obese patients suggests less attention was committed to provided health education. The lack of education and encouragement noted in the high weight bias group's response to the obese patients may also contribute to weaker practitioner-patient rapport, which obese women have reported being among the most important factors in healthcare settings (Buxton \& Snethen, 2013). Education and encouragement not only affect patient relationships with HCPs, but they help increase patient self-efficacy. According to the Health Belief Model theory of behavior change, self-efficacy is necessary in promoting healthy lifestyle modifications (Champio \& Skinner, 2008) and achieving better health status.

The words used in responses also suggests that HCPs express less empathy when dealing with obese patients. Empathy and compassion are not only ethical, but they allow patient- 
centered healthcare to succeed (Lown, Rosen, and Marttila, 2011). Positive provider-patient relationships characterized by understanding and concern have been showed to improve adherence to recommendations (Zolnierek and DiMatteo, 2009) such as diet and exercise modifications. Lown and colleagues (2011) found that physicians and patients consider compassion in healthcare to be very important ( $76 \%$ and $85 \%$ respectively), but less often see it practiced ( $58 \%$ and $53 \%$ respectively). Greater expression of empathy by HCPs may increase patient satisfaction and inspire greater adherence to lifestyle recommendations, specifically among the obese population. Instructing HCPs on the power of compassionate care may ultimately improve the health outcomes of obese patients by creating a more positive health environment.

Multiple sources identify the tendency of HCPs to focus on weight loss when dealing with obese patients (Bertakis \& Azari, 2005, Budd et al., 2011, Phelan et al., 2015). While this does not necessarily indicate poor quality of care, discussing behavior modifications aimed towards weight loss ignores the actual questions presented by the patient. In this study, HCPs with high weight bias counseling obese patients provided diet and exercise recommendations aimed towards weight loss and did not always forwardly address controlling cholesterol levels. Providing information regarding weight loss instead of "desired health outcomes" disobeys the Institute of Medicine's definition of quality of care (National Association for Healthcare Quality, 2005) and therefore, could be considered and indicator of poor quality of healthcare.

The tendency of all HCPs to prescribe statins to obese patients more readily than to normal weight patients may indicate that HCPs in both weight bias groups anticipated nonadherence to lifestyle recommendations by obese patients. HCPs were more willing to try diet and exercise modifications among non-obese patients and re-evaluate the necessity of 
pharmaceutical intervention at a later date. Obese people were given this chance less frequently. This may be attributed to a lack of confidence that obese patients would practice lifestyle modifications. This finding supports Huizinga et al. (2010) findings that higher patient BMI is associated with HCP perceived lower adherence to medication usage, alluding to a degree of patient mistrust. This parallels the notion that people associate "lazy" with obesity (Schwartz, Vartanian, Nosek, \& Brownell, 2006) and expect little motivation or action when making lifestyle changes. If HCPs are similarly judging obese patients as lazy, they are expressing weight bias. This may explain why obese patients were given less chance at lifestyle modification before resort to pharmaceutical intervention.

This study provides evidence that HCPs, particularly those with high weight bias, may benefit from interventions aimed at decreasing weight bias. To achieve this goal, Phelan et al. (2015) advocated for working with HCPs to improve weight biases that impact provider-patient relationships, creating a more weight neutral environment, and empowering patients to overcome situations in which they feel discriminated. As noted by Miller et al. (2013), many HCPs are unaware of their weight biases, and therefore may benefit from exploring their attitudes and perceptions of obese individuals. Conducting Health at Every Size ${ }^{\circledR}$ workshops, which preach size diversity and health through self-care, may inspire empathy and understanding of obese people's experiences. If HCPs developed more compassion towards obese people, it would help create a more inviting environment and encourage obese people to be more active in their healthcare.

Some of the strengths of this study include sample size and validity of data collection tools. The ATOP scale and use of scenarios are previously validated tools merited for measuring weight bias and quality of care respectively (DePierre \& Puhl, 2012; Peabody, Luck, Glassman, 
Dresselhaus \& Lee, 2000; Kaptanoglu \& Aktas, 2013), and use of silhouettes to depict patient BMI further strengthened the study design by providing visual representation of the hypothetical patients (Harris et al., 2008). Interpretation of qualitative data by two separate parties also adds strength to the thematic categories identified.

This study is not without limitations. Since this convenience sample attracted mostly female nurses practicing in Illinois, conclusions may not be generalized. Furthermore, the survey was distributed online, eliminating possible information regarding body language, time spent on the survey, and the working environment in which people completed the survey. The data collection methods used did also not differentiate between implicit and explicit weight bias, which may add further dimension to the findings. These extraneous factors may contribute to variability in participant response. Though the researchers did their best to objectively assess quality of care, the qualitative nature of this measurement can be challenging to capture.

Future research may benefit from comparing how different HCPs interact with patients of different weight categories. This could help identify practice areas with the most quality of care problems related to weight bias. Furthermore, research is needed comparing HCP weight bias and quality of care in different settings, for example outpatient versus inpatient, and in different geographical areas, such as urban versus rural communities. Since this research dealt with hypothetical patients, research may benefit from analyzing face-to-face provider-patient interactions. More research evaluating methods of eliminating weight bias from the health field would be valuable in ensuring HCPs deliver consistent quality of care across the patient population. 


\section{Conclusion}

In sum, this study provides evidence that there are notable disparities in quality of healthcare provided to obese versus normal weight patients. While HCPs in the high weight bias group more frequently treated obese patients differently, HCPs in the low weight bias group also provided different medication recommendations to obese patients versus normal weight patients. While big picture recommendations were similar among all groups, the presentation of these recommendations differed when providing care to obese and non-obese patients. HCPs with high weight bias tended to deliver health advice to obese patients with an air of judgment exemplifying lower quality of care to obese patients. The findings of this study suggest a need to educate HCPs on the importance of empathy and compassion when providing treatment to all patients, regardless of weight, to improve patient outcomes. 


\section{CHAPTER II: EXTENDED LITERATURE REVIEW}

\section{Obesity Prevalence}

The Center for Disease Control and Prevention (CDC) estimates that $36.5 \%$ of American adults classify as obese (Ogden, Carroll, Fryar \& Flegal, 2015). Obesity is defined by a Body Mass Index (BMI), which is calculated using height and weight, of greater than 30 (CDC, 2015). Obesity has been identified as a critical public health problem as obesity rates have increased across the county effecting people of all ages, socioeconomic statuses, and ethnicities (Ogden et al., 2015).

It is generally understood that obesity is a multifactorial problem with modifiable and non-modifiable risk factors (CDC, 2015; Rippe \& Angelopoulos, 2012; Kushner, Lawrence, Kumar \& Lau, 2013). Excessive calorie intake, inadequate energy expenditure, and genetic predisposition in the right combination are theorized to result in obesity (CDC, 2015; Rippe \& Angelopoulos, 2012; Kushner et al., 2013). This may combine with extraneous factors such as stress (Torres \& Nowson, 2007), food access (Wolters \& Steel, 2016), and environmental chemicals (Tang-Pernonard, Andersen, Jensen \& Heitmann, 2011) to increase the risk of morbid weight gain.

This is concerning because obesity is associated with comorbidities such as diabetes, heart disease, and some cancers (CDC, 2016), placing obese people at a high risk for health events. The adverse health effects connected to obesity have raised concerns about the financial consequences of excess body weight. Finkelstein, Trogdon, Cohen and Dietz (2009) estimated that $42 \%$ more healthcare dollars are spent on obese people compared to normal weight people, amounting to as much as $\$ 147$ billion in obesity-related health costs in 2008 . As obesity rates 
continue to amount to over one-third of the American population (Ogden et al., 2015), one can speculate that healthcare costs related to obesity are likely to increase as well.

\section{Treatment of Obesity}

The concern about obesity prevalence, cost, and quality of life have led health professionals to take action against America's weight problem. Recognized professional health organizations are in agreement that weight loss, diet, and exercise modifications can reverse the health risks associated with obesity (American Heart Association, 2015; Raynor \& Champagne, 2016; American Cancer Society, 2016). The American Heart Association (2015) encourages HCPs to recognize obesity as a disease and promote prescriptive weight loss for more aggressive treatment. These treatment recommendations largely place responsibility and accountability on the obese individual.

In some instances, pharmaceutical and surgical interventions are deemed appropriate to assist with weight management in addition to diet and exercise. Weight management medications have shown success in minor weight loss (3-9\%) in conjunction with lifestyle modifications (Yanovski \& Yanovski, 2013). Pharmacotherapy for obesity, however, is not utilized as often as most guidelines recommend (Kahan, 2016). This may be related to past safety concerns with early weight loss drugs (Rippe \& Angelopoulos, 2012; Kushner et al., 2013). One drug that remains on the market is Orlistat, also sold under the name of Alli and Xenical, which works by interfering with nutrient absorption in the gut (Rippe \& Angelopoulos, 2012). Orlistat is sometimes chosen to assist with weight loss and diabetes management in obese adults and adolescents (Rippe \& Angelopoulos, 2012; Kushner et al., 2013) with the ultimate goal of improving health status. 
When lifestyle modifications prove ineffective, bariatric surgery can be used to stimulate weight loss. The National Institute of Diabetes and Digestive and Kidney Diseases (2016), a branch of the National Institute of Health, indicates that those diagnosed with morbid obesity and one or more comorbidities (i.e. diabetes, heart disease, sleep apnea) qualify for bariatric surgery. There are different types of bariatric surgery with different mechanisms of achieving weight loss (Rippe \& Angelopoulos, 2012; Kushner et al., 2013). Bariatric surgery as a whole is considered an effective approach to weight loss among the severely obese population (Picot et al., 2009). In addition, weight loss resulting from bariatric surgery typically improves other health factors such as type two diabetes, dyslipidemia, hypertension, and obstructive sleep apnea (Kushner et al., 2013). There are risks associated with the surgery, however, and post-surgery complications are not uncommon (Rippe \& Angelopoulos, 2012). Since bariatric surgery is a life-changing undertaking, pre- and post-operative management involving the patient and a multidisciplinary team are usually required (CDC, 2015; Rippe \& Angelopoulos, 2012; Kushner et al., 2013) When discussing treatment of obesity, psychological health should be considered along with physiological health. Kushner et al. (2013) describe the increased risk of mental health issues among the obese population. In a culture in which healthy, happy, successful, and thin are synonymous, carrying excess weight can influence a person's stress level and self-esteem (Kushner et al, 2013). This may explain why obesity is accompanied by higher rates of depression and anxiety compared to rates in the normal weight population (Kushner et al., 2013). Since mental health is a component of well-being that can influence other health aspects, it is important to address mental health when treating obesity. 


\section{Weight Bias}

The prevalence and manifestation of weight bias in American culture is well established. A historical analysis conducted in 2010 concluded that stigmatization of obese people generates health disparities, threatens health, and interferes with effective obesity intervention (Puhl \& Heuer, 2010). Furthermore, Puhl and Heuer (2010) found that children as young as three-yearsold exhibit this type of socially-acceptable attitude. This likely increases obese individual's lifelong physical and psychological health risks, including utilization of health care.

Stigma, which is part of the social meaning of a disease, is a noted barrier to treatment (Pomeranz, 2008; Puhl \& Heuer, 2010). Negative attitudes towards obese persons have been associated with unhealthy behaviors such as binge-eating and lower physical activity levels (Puhl \& Heuer, 2010). Disease stigma is not new to the US and has historically been associated with other health conditions such as tuberculosis and Human Immunodeficiency Virus/Acquired Immunodeficiency Syndrome (HIV/AIDS) (Puhl \& Heuer, 2010, Pomeranz, 2008). In these populations, individuals were blamed for their diseases as obese individuals are today, further alienating the stigmatized population from the health world (Puhl \& Heuer, 2010). Negatively labeling diseases can create risk for increased morbidity and mortality related to the shame in seeking healthcare.

Weight bias is reflected on a cultural level in United States, fostering a community in which discrimination by weight is generally accepted. In fact, weight bias among Americans has increased alongside the rising levels of obesity (Andreyeyva, Puhl, \& Brownell, 2008) further alienating the obese population. Institutionalized bias may be detected in media attention towards the obesity crisis. Public health campaigns aiming to combat the obesity epidemic inadvertently discriminate against overweight and obese individuals (Puhl, Peterson, \& Luedicke, 2013) by 
inspiring nation-wide disrespect towards the overweight population (Puhl \& Heuer, 2010). As summarized by Walls Peeters, Proietto, and McNeil (2011), anti-obesity campaigns can distort the public's perception of healthy bodies and push obese people towards high-risk weight loss measures such as drugs and surgery. Puhl and Heuer (2010) concluded there is a need to be aware of how attitudes about body size can negatively impact health status. Stigmatizing antiobesity messages have been identified by the public as negative and not motivating (Puhl, Peterson, \& Luedicke, 2013) further discouraging healthy lifestyle modifications. This communal expression of weight bias may generate negative attitudes towards obese individuals without the public's awareness.

Examining implicit and explicit weight biases explores the depth and universality of weight bias. In one study, anti-fat attitudes were measured by asking participants to associate different characteristic words with different weight descriptions (Schwartz, Vartanian, Nosek, \& Brownell, 2006). The results revealed that people associated "fat" with negative attributes such as lazy, "thin" with positive attributes such as motivated (Schwartz et al., 2006). Interestingly, Schwartz et al. (2006) found that obese and non-obese respondents exhibited similar levels of weight stereotyping and implicit weight biases against overweight people, though anti-fat bias was significantly lower among those with higher BMI. This suggests the unquestionable nature of weight-related stereotypes and identifies that negative attitudes towards obese people exist on an unconscious level. This important finding reveals that most people have weight biases and are unaware of this bias, which may be ingrained in American culture.

A comprehensive historical analysis by Pomeranz (2008) concluded that challenging weight bias is necessary because when weight discrimination is socially acceptable, as it is today, obese individuals suffer from an institutionalized bias. In the past, groups such as African 
Americans and homosexuals have experienced extreme institutionalized discrimination, in which cases, it took legislative changes to give discriminated groups equal standing in society (Pomeranz, 2008). If this population was less stigmatized and more cared about as individuals, there would be more concern about those who are suffering and greater success in promoting healthy lifestyle behaviors (Pomeranz, 2008). Ignoring the negative effects of weight bias ignores the concerns of overweight and obese individuals who make up two-thirds of the American population (Ogden, 2012). Addressing weight stigma may even be instrumental in improving the health of obese Americans.

\section{Healthcare Professionals and Weight Bias}

Healthcare settings are a known source of weight stigma where healthcare professionals are likely to blame all health problems on weight, creating a barrier to utilization of health care (Brown et al., 2006; Phelan et al., 2015; Puhl \& Heure, 2010). Brown, Thompson, Tod, and Jones (2006) interviewed 28 obese patients to learn about their experiences with primary care physicians and found that obese participants were ambivalent about seeking health advice because of their weight status. Patient ambivalences were founded in weight being addressed over other health problems, embarrassment of personal responsibility for weight, and HCPs relating all patient problems to weight (Brown et al., 2006). Sikorski et al. (2013) distributed a questionnaire in Germany seeking to measure HCPs attitude towards obese women using patient vignettes. They concluded that $99 \%$ of participant's exhibited weight bias and HCPs attribute obesity to personal responsibility, which increases judgmental attitudes towards people of size (Sikorski et al., 2013).

Physicians have been associated with negative attitudes and decreased respect for overweight and obese patients (Huizinga et al., 2009; Sikorsky et al., 2013). Huizinga and 
colleagues (2009) completed a secondary data analysis of information from the Patient-Physician Partnership Study, which took place in Baltimore, MD. The research team examined physicianreported respect for patients and found that physicians reported significantly lower respect for patients with higher BMIs (Huizinga et al., 2009). A randomized control trial studying physicianpatient communication patterns and perception of adherence to recommendations found that higher patient BMI was also associated with HCP perception of non-adherence to medication prescriptions (Huizinga et al., 2010). This collection of findings supports the idea that physicians have negative views of overweight and obese patients.

Medical students are the future of the healthcare field; thus their weight bias levels are important to examine as well. A notable study by Miller and colleagues (2013) measured the prevalence of implicit and explicit weight biases among 310 third-year medical students at the Wake Forest School of Medicine. Results revealed that $72 \%$ of students preferred thin patients to fat patients, males were twice as likely to report weight biases, $56 \%$ had unconscious weight biases, and only $23 \%$ of students who had weight biases were aware of this prejudice (Miller et al., 2013). The fact that a majority of students were unaware of their weight biases is concerning because these future HCPs may be more likely to express and provide care based on their unconscious negative attitudes towards overweight and obese patients. Implicit negative attitudes towards obese people has similar been seen in nursing and psychology students (Waller, Lampman \& Lupfer-Johnson, 2012). Persky and Eccleston (2011) evaluated weight bias in another population of medical students by asking them to respond to randomly assigned virtual female obese or non-obese patients with identical medical profiles. Medical students showed more negative stereotyping, less anticipated patient adherence to recommendations, worse perceived patient health, and less observed eye contact with an obese patient versus the identical 
situation with a normal weight patient (Persky \& Eccleston, 2011). That being said, much is still unknown regarding how these perceptions of obese people impact healthcare provided.

Though less attention has been given to weight bias in other healthcare professionals, it is important to examine bias in specialty disciplines. Diet and exercise play major roles in weight maintenance, but little research studies weight bias among the professionals who model these lifestyle behaviors including dietitians and personal trainers. One study investigating weight bias among dietetic students used the Fat Phobia Scale and responses to hypothetical patients to measure attitudes towards obese clients (Puhl, Wharton \& Heuer, 2009). Puhl et al. (2009) concluded the students exhibited moderate levels of fat phobia, anticipated obese clients to disregard diet recommendations, and rated obese individual's diets poorer even though health information was identical to that of the normal weight client. This is consistent with attitudes of other HCPs who anticipate non-adherence to medication recommendations by obese patients (Huizinga et al., 2010), and illustrates pre-determined judgment about lifestyle habits based on weight status.

In addition, nurses' weight bias has been established, though they appear to exude lower levels of bias compared to other HCPs (Sikorski et al., 2013). Tanneberger and Ciuputu-Plath (2017) conducted a survey among German nurses and found that nurses perceived weight bias to be among the major reasons discrimination towards obese patients exists in healthcare settings. Furthermore, placing more blame on the individual for obesity was associated with higher levels of weight bias among nurses (Tanneberger \& Ciupitu-Plath, 2017) similar to previous findings evaluating blame and levels of prejudice (Sikorski et al., 2013). Both of these studies were conducted outside of the United States, however, so cannot adequately describe attitudes among 
American nurses. Few studies have examined nurses' attitudes towards obese patients during this decade, justifying a need to reexamine how nurses feel and act towards this patient population.

\section{Quality of Care}

The Institute of Medicine describes quality of care as "the extent to which health services provided to individuals and patient populations improve desired health outcomes" (National Association for Healthcare Quality, 2005). Two recent comprehensive literature reviews adequately summarize the current body of research regarding weight bias and quality of healthcare. Budd et al. (2011) concluded that obese people are more likely to delay seeking medical care because of fear of disrespectful treatment, anticipation of unsolicited weight loss advice, embarrassment of being weighed, and fear that equipment will be too small. However, the research team found that though physicians have significant negative attitudes towards overweight and obese patients, delivery of care methods was not affected (Budd et al. 2011). Conversely, a more recent review of current literature by Phelan and colleagues (2015) found that weight bias may impact quality of care. Specifically, HCPs reported less respect for obese patients than normal weight patients, viewed obese people as a waste of time and spent less time giving them health education than normal weight counterparts (Phelan et al. 2015). Furthermore, HCPs perceive that obese people adhere less to recommendations, deliver less patient-centered care to obese patients, and do not feel comfortable nor know how to approach obesity in the doctor's office (Phelan et al. 2015). Findings indicated that overall, HCPs also over-attribute all symptoms to obesity and weight issues and do not look further into other possible health factors

(Phelan et al., 2015). This weight discrimination seems unintentional, but does exist in healthcare settings based on available literature (Budd et al., 2011; Phelan et al., 2015). 
Buxton and Snethen (2013) conducted an interview study with a population of 26 Pennsylvania women, which explored the perception of healthcare experiences with primary care physicians. Obese women reported that the most important factors in healthcare settings are their perceptions health care, feeling respected as patients, and establishment of a connection with HCPs (Buxton \& Snethen, 2013). To further examine the relationship between patient and HCP, a cross-sectional analysis of audio-recorded physician-patient communication revealed that HCPs had less emotional rapport with patients with higher BMIs than those of normal weight (Gudzune, Beach, Roter, \& Cooper, 2013). This perpetuates inequities in care when obese women report relationships with HCPs as major factors in healthcare quality and physicians report less rapport with obese patients (Buxton \& Snethen, 2013; Gudzune et al., 2013). Another study examining healthcare experiences used a randomized prospective design to investigate how obesity influenced HCP practices through analysis of patient health data and videotapes of physician visits (Bertakis \& Azari, 2005). Bertakis and Azari (2005) found that patient BMI was not associated with length of visit, but did impact what happened during visit including less time talking about health, more time discussing exercise, and more time spent on unrelated nutrition discussion (Bertakis \& Azari, 2005).

Though these differences in care provided to obese patients have been observed in the literature, they have not been liked to weight bias. Few studies compare level of weight bias directly to quality of care outcomes, and those that do have been conducted outside of the United States. There is a need to understand whether weight bias is responsible for negative quality of care indicators to be able to adequately train HCPs to provide consistent quality of care across patient population. 


\section{REFERENCES}

American Cancer Society. (2016). Body weight and cancer risk. Retrieved from

http://www.cancer.org/cancer/cancer-causes/diet-physical-activity/body-weight-and-cancerrisk/health-issues.html

American Heart Association. (2015). Treating obesity as a disease. Retrieved from http://www.heart.org/HEARTORG/HealthyLiving/WeightManagement/Obesity/TreatingObesity-as-a-Disease_UCM_459557_Article.jsp\#.WIQZj3eZOt8

Andreyeva, T., Puhl, R. M., \& Brownell, K. D. (2008). Changes in perceived weight discrimination among americans, 1995-1996 through 2004-2006. Obesity (Silver Spring, Md.), 16(5), 1129-1134. doi:10.1038/oby.2008.35

Bertakis, K. D., \& Azari, R. (2005). The impact of obesity on primary care visits. Obesity Research, 13(9), 1615-1623. doi:10.1038/oby.2005.198

Brown, I., Thompson, J., Tod, A., \& Jones, G. (2006). Primary care support for tackling obesity: A qualitative study of the perceptions of obese patients. The British Journal of General Practice : The Journal of the Royal College of General Practitioners, 56(530), 666-672.

Budd, G. M., Mariotti, M., Graff, D., \& Falkenstein, K. (2011). Health care professionals' attitudes about obesity: An integrative review. Applied Nursing Research : ANR, 24(3), 127137. doi:10.1016/j.apnr.2009.05.001

Buxton, B. K., \& Snethen, J. (2013). Obese women's perceptions and experiences of healthcare and primary care providers: A phenomenological study. Nursing Research, 62(4), 252-259. doi:10.1097/NNR.0b013e318299a6ba

Center for Disease Control and Prevention. (2015). Overweight and obesity. Retrieved from https://www.cdc.gov/obesity/adult/causes.html 
Champio, V. \& Skinner, C. (2008) The Health Belief Model. In Glanz, K., Rimer, B., \& Viswanath, K. (Eds.), Health behavior and health education: Theory, research, and practice (45-50). San Francisco, CA : Jossey-Bass.

DePierre, J. A., \& Puhl, R. M. (2012). Experiences of weight stigmatization: A review of selfreport assessment measures. Obesity Facts, 5(6), 897-918. doi:10.1159/000346259 [doi]

Finkelstein, E. A., Trogdon, J. G., Cohen, J. W., \& Dietz, W. (2009). Annual medical spending attributable to obesity: Payer-and service-specific estimates. Health Affairs (Project Hope), 28(5), w822-31. doi:10.1377/hlthaff.28.5.w822

Gudzune, K. A., Beach, M. C., Roter, D. L., \& Cooper, L. A. (2013). Physicians build less rapport with obese patients. Obesity (Silver Spring, Md.), 21(10), 2146-2152. doi:10.1002/oby.20384

Harris, C. V., Bradlyn, A. S., Coffman, J., Gunel, E., \& Cottrell, L. (2008). BMI-based body size guides for women and men: Development and validation of a novel pictorial method to assess weight-related concepts. International Journal of Obesity (2005), 32(2), 336-342. doi:0803704

Hebl, M. R., Xu, J., \& Mason, M. F. (2003). Weighing the care: Patients' perceptions of physician care as a function of gender and weight. International Journal of Obesity and Related Metabolic Disorders : Journal of the International Association for the Study of Obesity, 27(2), 269-275. doi:10.1038/sj.ijo.802231

Huizinga, M. M., Bleich, S. N., Beach, M. C., Clark, J. M., \& Cooper, L. A. (2010). Disparity in physician perception of patients' adherence to medications by obesity status. Obesity (Silver Spring, Md.), 18(10), 1932-1937. doi:10.1038/oby.2010.35 
Huizinga, M. M., Cooper, L. A., Bleich, S. N., Clark, J. M., \& Beach, M. C. (2009). Physician respect for patients with obesity. Journal of General Internal Medicine, 24(11), 1236-1239. doi:10.1007/s11606-009-1104-8

Kahan, S. (2016). Obesity guidelines. Bariatric Times, 13(12), C4-C8.

Kaptanoğlu, A. Y., \& Aktaş, I. (2013). Measuring quality of care using a vignette-based survey in turkish hospitals, Kuwaiti Journal of Health Care Management, 1(1), 5-7. doi:c.kjh.com/1/1/5-7

Kushner, R., Lawrence, V., Kumar, S., \& Lau, N. (2013). Practical manual of clinical obesity (1st ed.). Somerset: Wiley.

Lown, B. A., Rosen, J., \& Marttila, J. (2011). An agenda for improving compassionate care: A survey shows about half of patients say such care is missing. Health Affairs (Project Hope), 30(9), 1772-1778. doi:10.1377/hlthaff.2011.0539

Ma, J., Xiao, L., \& Stafford, R. S. (2009). Adult obesity and office-based quality of care in the united states. Obesity (Silver Spring, Md.), 17(5), 1077-1085. doi:10.1038/oby.2008.653

Miller, D. P.,Jr, Spangler, J. G., Vitolins, M. Z., Davis, S. W., Ip, E. H., Marion, G. S., \& Crandall, S. J. (2013). Are medical students aware of their anti-obesity bias? Academic Medicine : Journal of the Association of American Medical Colleges, 88(7), 978-982. doi:10.1097/ACM.0b013e318294f817

National Association for Healthcare Quality (U.S.). (2005). Q solutions : Essential resources for the healthcare quality professional. Glenview, IL: National Association for Healthcare Quality. 
National Institute of Diabetes and Digestive and Kidney Diseases. (2016). Potential candidates of bariatric surgery. Retrieved from https://www.niddk.nih.gov/health-information/healthtopics/weight-control/bariatric-surgery/Pages/potential-candidates.aspx.

Ogden, C. L., Carroll, M. D., Kit, B. K., \& Flegal, K. M. (2012). Prevalence of obesity in the united states, 2009-2010. NCHS Data Brief, (82)(82), 1-8.

Ogden, C. L., Carroll, M. D., Fryar, C. D., \& Flegal, K. M. (2015). Prevalence of obesity among adults and youth: United states, 2011-2014. NCHS Data Brief, (219)(219), 1-8.

Peabody, J. W., Luck, J., Glassman, P., Dresselhaus, T. R., \& Lee, M. (2000). Comparison of vignettes, standardized patients, and chart abstraction: A prospective validation study of 3 methods for measuring quality. Jama, 283(13), 1715-1722. doi:joc91362

Persky, S., \& Eccleston, C. P. (2011). Medical student bias and care recommendations for an obese versus non-obese virtual patient. International Journal of Obesity (2005), 35(5), 728735. doi:10.1038/ijo.2010.173

Phelan, S. M., Burgess, D. J., Yeazel, M. W., Hellerstedt, W. L., Griffin, J. M., \& van Ryn, M. (2015). Impact of weight bias and stigma on quality of care and outcomes for patients with obesity. Obesity Reviews : An Official Journal of the International Association for the Study of Obesity, 16(4), 319-326. doi:10.1111/obr.12266

Picot, J., Jones, J., Colquitt, J. L., Gospodarevskaya, E., Loveman, E., Baxter, L., \& Clegg, A. J. (2009). The clinical effectiveness and cost-effectiveness of bariatric (weight loss) surgery for obesity: A systematic review and economic evaluation. Health Technology Assessment (Winchester, England), 13(41), 1. doi:10.3310/hta13410 
Pomeranz, J. L. (2008). A historical analysis of public health, the law, and stigmatized social groups: The need for both obesity and weight bias legislation. Obesity (Silver Spring, Md.), 16 Suppl 2, S93-103. doi:10.1038/oby.2008.452

Puhl, R., Luedicke, J., \& Peterson, J. L. (Jul 2013). Public reactions to obesity-related health campaigns: A randomized controlled trial. American Journal of Preventive Medicine, 45(1), 36-48. doi:http://dx.doi.org/10.1016/j.amepre.2013.02.010

Puhl, R., Peterson, J. L., \& Luedicke, J. (2013). Fighting obesity or obese persons? public perceptions of obesity-related health messages. International Journal of Obesity (2005), 37(6), 774-782. doi:10.1038/ijo.2012.156

Puhl, R., Wharton, C., \& Heuer, C. (2009). Weight bias among dietetics students: Implications for treatment practices. Journal of the American Dietetic Association, 109(3), 438-444. doi:10.1016/j.jada.2008.11.034

Puhl, R. M., \& Heuer, C. A. (2010). Obesity stigma: Important considerations for public health. American Journal of Public Health, 100(6), 1019-1028. doi:10.2105/AJPH.2009.159491

Raynor, H. A., \& Champagne, C. M. (2016). Position of the academy of nutrition and dietetics: Interventions for the treatment of overweight and obesity in adults. Journal of the Academy of Nutrition and Dietetics, 116(1), 129-147. doi:10.1016/j.jand.2015.10.031

Rippe, J. M., \& Angelopoulos, T. J. (2012). Obesity : Prevention and treatment (1st ed.). London: CRC Press.

Schwartz, M. B., Chambliss, H. O., Brownell, K. D., Blair, S. N., \& Billington, C. (2003). Weight bias among health professionals specializing in obesity. Obesity Research, 11(9), 1033-1039. doi:10.1038/oby.2003.142 
Schwartz, M. B., Vartanian, L. R., Nosek, B. A., \& Brownell, K. D. (2006). The influence of one's own body weight on implicit and explicit anti-fat bias. Obesity (Silver Spring, Md.), 14(3), 440-447. doi:14/3/440

Sikorski, C., Luppa, M., Glaesmer, H., Brahler, E., Konig, H. H., \& Riedel-Heller, S. G. (2013). Attitudes of health care professionals towards female obese patients. Obesity Facts, 6(6), 512-522. doi:10.1159/000356692

Tang-Peronard, J., Andersen, H. R., Jensen, T. K., \& Heitmann, B. L. (2011). Endocrinedisrupting chemicals and obesity development in humans: A review. Obesity Reviews, 12(8), 622-636. doi: 10.1111/j.1467-789X.2011.00871.x.

Tanneberger, A., \& Ciupitu-Plath, C. (2017). Nurses' weight bias in caring for obese patients. Clinical Nursing Research, 1054773816687443. doi:10.1177/1054773816687443

Teachman, B. A., \& Brownell, K. D. (2001). Implicit anti-fat bias among health professionals: Is anyone immune? International Journal of Obesity and Related Metabolic Disorders : Journal of the International Association for the Study of Obesity, 25(10), 1525-1531. doi:10.1038/sj.ijo.0801745

Torres, S. J., \& Nowson, C. A. (2007). Relationship between stress, eating behavior, and obesity. Nutrition, 23(11), 887-894. doi:10.1016/j.nut.2007.08.008

Waller, T., Lampman, C., \& Lupfer-Johnson, G. (2012). Assessing bias against overweight individuals among nursing and psychology students: An implicit association test. Journal of Clinical Nursing, 21(23-24), 3504-3512. doi:10.1111/j.1365-2702.2012.04226.x

Walls, H. L., Peeters, A., Proietto, J., \& McNeil, J. J. (2011). Public health campaigns and obesity - a critique. BMC Public Health, 11, 136-2458-11-136. doi:10.1186/1471-2458-11136 
Wolters, E. A., \& Steel, B. S. (2016). Sustainable futures: Healthy lifestyles, obesity, and access to food in U.S. counties 2012. Agriculture and Agricultural Science Procedia, 8, 73-80. doi:10.1016/j.aaspro.2016.02.010

Yanovski, S. Z., \& Yanovski, J. A. (2014). Long-term drug treatment for obesity: A systematic and clinical review. JAMA, Journal of the American Medical Association, 311(1), 74-86.

Zolnierek, K. B., \& Dimatteo, M. R. (2009). Physician communication and patient adherence to treatment: A meta-analysis. Medical Care, 47(8), 826-834.

doi:10.1097/MLR.0b013e31819a5acc 
APPENDIX A: DATA COLLECTION TOOLS 


\section{Informed Consent}

\section{Informed Consent to Participate in a Research Study}

You are invited to participate in a research study to understand how healthcare professionals provide care. You have been invited to participate because you are a professional in the healthcare field. The purpose of this research study is to compare and contrast different responses to questions about healthcare procedure.

Your participation in this study involves completion of a demographic questionnaire and a 22-item survey. Two questions will ask for a short response to two similar scenarios and the last twenty questions will ask you your opinions about different statements related to obese persons. Completion of the survey may take less than 20 minutes. You will be asked to answer several basic demographic questions including age, sex, and race, but the survey is anonymous in nature. No identifiable information will be collected and all information will be confidential. These questions will be asked only once. You can complete this survey at any location with a computer that is convenient for you. We will not be contacting you again after this study.

We believe that there are no more than minimal risks of everyday life associated with this research study. Participants may benefit from the findings and conclusions reported at the completion of the study, but will not experience immediate benefits upon completion.

Participation in this research study is voluntary. You do not have to participate in this study if you do not want to. By agreeing to these terms, you agree to consent to the procedure. Participants are able to discontinue participation in this survey at any time without consequences if he or she wishes. There are also no consequences for not participating in this survey.

To protect your personal information, a number will be assigned to you based on your entry into the study. No names or identifiable information will be used or recorded during the study. All responses will be stored in a locked office on a password protected computer in Room 203K of the Turner Hall Building, Normal, IL. At the conclusion of the study, researchers may publish their findings.

To thank you for your time and effort, when you complete the study, you can choose to enter yourself into a drawing for one of two $\$ 100$ Amazon gift cards that will be delivered to you via email. In order to be entered into the drawing, you will need to click on the link at the end of the anonymous survey to take you to another site where we will need to collect your name, email address, and mailing address. This information is only being collected for purposes of distributing the gift card; it will not be linked to your survey responses or retained for other purposes. Please note that compensation for participation in research may be taxable.

If you have any questions, comments, or concerns regarding this research study, please feel free to contact the Principal Investigator Dr. Rachel Vollmer by phone: xxx-xxx-xxxx or email: xxxxxxx@xxxxx.xxx for any questions regarding the rights of research participants or research-related injury or adverse effects feel free to contact the Illinois State University 
Research Ethics and Compliance Office by phone: $x x x-x x x-x x x x$ or by email: xxx@xxxxx.xxx

IRB Approval Number: $\mathrm{xxxxxx- \textrm {x }}$

By clicking agree, you are indicating that you have read this informed consent form and indicate consent to participate.

$\underline{\text { Agree }}$ 


\section{ATOP Questionnaire}

Please mark each statement below in the left margin, according to how much you agree or disagree with it. Please do not leave any blank. Use the numbers on the following scale to indicate your response. Be sure to place a minus or plus sign $(-$ or + ) beside the number that you choose to show whether you agree or disagree.

$\begin{array}{cccccc}-\mathbf{3} & -2 & -1 & +\mathbf{1} & +2 & +\mathbf{3} \\ \text { I strongly } & \text { I moderately } & \text { I slightly } & \text { I slightly } & \text { I moderately } & \text { I strongly } \\ \text { disagree } & \text { disagree } & \text { disagree } & \text { agree } & \text { agree } & \text { agree }\end{array}$

Obese people are as happy as nonobese people.

Most obese people feel that they are not as good as other people.

Most obese people are more self-conscious than other people.

Obese workers cannot be as successful as other workers.

Most nonobese people would not want to marry anyone who is obese.

Severely obese people are usually untidy.

Obese people are usually sociable.

Most obese people are not dissatisfied with themselves.

Obese people are just as self-confident as other people.

Most people feel uncomfortable when they associate with obese people.

Obese people are often less aggressive than nonobese people.

Most obese people have different personalities than nonobese people.

Very few obese people are ashamed of their weight.

Most obese people resent normal weight people.

Obese people are more emotional than nonobese people.

Obese people should not expect to lead normal lives.

Obese people are just as healthy as nonobese people.

Obese people are just as sexually attractive as nonobese people.

Obese people tend to have family problems.

One of the worst things that could happen to a person would be for him to become obese.

\section{ATOP Scoring Guidelines}

Step 1: Multiply the response to the following items by-1(i.e., reverse the direction of scoring):

- Item 2 through Item 6, Item 10 through Item 12, Item 14 through Item 16, Item 19 and Item 20

Step 2: Add up the responses to all items.

Step 3: Add 60 to the value obtained in Step 2. This value is the ATOP score.

Higher numbers indicate more positive attitudes. 


\section{Scenarios with Silhouettes}

\section{Scenario A}

Patient A is a 42-year old female who has been newly diagnosed with hypercholesterolemia. She is 5' 6" and $140 \mathrm{lbs}$. with a BMI of 22. She has a sedentary office job, is married, and has two children in elementary school. She is concerned about her blood lipid profile and would like help from her doctor on what do to. With the given information, describe how you would treat this patient in at least 2-3 sentences.

\section{Scenario B}

Patient B is a 42-year old female who has been newly diagnosed with hypercholesterolemia. She is 5' 6" and $200 \mathrm{lbs}$. with a BMI of 32. She has a sedentary office job, is married, and has two children in elementary school. She is concerned about her blood lipid profile and would like help from her doctor on what do to. With the given information, describe how you would treat this patient in at least 2-3 sentences.

\section{Scenario C}

Patient $\mathrm{C}$ is a 42-year old male who has been newly diagnosed with hypercholesterolemia. He is 6' 0" and $165 \mathrm{lbs}$. with a BMI of 22. He has a sedentary office job, is married, and has two children in elementary school. He is concerned about his blood lipid profile and would like help from his doctor on what do to. With the given information, describe how you would treat this patient in at least 2-3 sentences.

\section{Scenario D}

Patient $\mathrm{D}$ is a 42-year old male who has been newly diagnosed with hypercholesterolemia. He is 6" 0" and $235 \mathrm{lbs}$. with a BMI = 32. He has a sedentary office job, is married, and has two children in elementary school. He is concerned about his blood lipid profile and would like help from his doctor on what do to. With the given information, describe how you would treat this patient in at least 2-3 sentences. 